\title{
INFLUENCE OF ANNEALING AND OPTICAL AGING ON OPTICAL AND STRUCTURAL PROPERTIES OF ZnO THIN FILMS OBTAINED BY SILAR METHOD
}

\author{
C. Duman ${ }^{a}$ and H. Guney ${ }^{b}$ \\ ${ }^{a}$ Electrical and Electronics Engineering Department, Faculty of Engineering and Architecture, \\ Erzurum Technical University, 25700 Yakutiye, Erzurum, Turkey \\ ${ }^{\mathrm{b}}$ Central Application and Research Laboratory (MERLAB), Agri Ibrahim Cecen University, \\ Erzurum Yolu, 04100 Agri, Turkey \\ Email: caglarduman@erzurum.edu.tr; hguney@agri.edu.tr
}

Received 7 May 2017; revised 21 June 2017; accepted 20 September 2017

\begin{abstract}
In this study, zinc oxide ( $\mathrm{ZnO}$ ) thin films are deposited on fluorine doped tin oxide (FTO) substrates by using a successive ionic layer adsorption and reaction (SILAR) method. One of the samples is not annealed and others are annealed at 200,400 and $600{ }^{\circ} \mathrm{C}$, and all the samples are aged under ultraviolet (UV) light for $19 \mathrm{~h}$.

These samples are used to investigate the effect of annealing and aging on the properties of $\mathrm{ZnO}$. Structural properties of the $\mathrm{ZnO}$ thin films are examined with scanning electron microscopy (SEM) and X-ray diffraction (XRD). Photoluminescence, transmittance and absorption measurements are used to observe the optical properties of the films. In the literature, there is no study investigating the effect of aging on $\mathrm{ZnO}$ thin films deposited with the SILAR method, hence this study fills the gap in the literature.
\end{abstract}

Keywords: $\mathrm{ZnO}$ thin film, annealing, aging, SILAR

PACS: 71.55.Gs, 74.62.Bf, 77.55.hf, 78.20-e

\section{Introduction}

$\mathrm{ZnO}$ is a direct band gap semiconductor with a band gap energy of circa $3.4 \mathrm{eV}$. It is transparent over all visible wavelengths and its conductivity can be changed from a semi-insulator to a semimetal depending on its thickness and doping level. Also $\mathrm{ZnO}$ thin films show very high piezoelectric and relatively high thermoelectric properties. Applications of $\mathrm{ZnO}$ technology include development of solar cells, light emitting diodes, displays and sensors [1].

$\mathrm{ZnO}$ can be deposited on various substrates as a thin film. The synthesis methods are basically classified as vapour phase and solution based techniques. The solution based synthesis has such advantages as lower cost, lower temperature requirements, scalability and easier handling compared to those of the vapour phase synthesis. Organic and inorganic substrates can be used in the solution based methods, and deposition occurs in both aqueous and organic solutions or in a mixture of them [2]. There are several methods used for $\mathrm{ZnO}$ thin film deposition in the literature including the SILAR method, sol-gel method, chemical bath deposition, spray pyrolysis, pulsed laser deposition, atomic layer deposition and electron beam evaporation technique. SILAR is a simple and economic solution based method in which $\mathrm{ZnO}$ thin films are formed from an aqueous solution. Factors affecting the deposition process are the quality of precursor solutions, their concentrations, $\mathrm{pH}$ values, complexing agents and individual rinsing and immersion time periods [3]. Although crystal structures of $\mathrm{ZnO}$ thin films are highly dependent on the method used and the process parameters, in general, they form a hexagonal wurtzite crystal structure with high densities [ [4]. 
In the literature, there are several studies available about the effects of aging on optical, structural and electrical properties of $\mathrm{ZnO}$ and other thin films, however, to the best of our knowledge, there is no study investigating the aging process of $\mathrm{ZnO}$ thin films deposited using the SILAR method. Optical measurements of aged $\mathrm{ZnO}$ thin films show that UV transmittance and green band emission decrease and near band edge UV emission increases. Also their absorption edges shift to higher energies [5-10]. Effects of aging on thin films obtained via the SILAR method for other materials have been explored in the literature. In one of these studies, it is shown that the current-voltage characteristic of $\mathrm{Cd} / \mathrm{CdS} / \mathrm{n}$-Si prepared via the SILAR method is enhanced by aging while other electrical characteristics are only slightly changed [11]. In another study, it is demonstrated that the electrical parameters of $\mathrm{Cu} / \mathrm{CuS} / \mathrm{n}-\mathrm{GaAs}$ obtained with the SILAR method do not change significantly with aging [12]. Also, it is observed that a $\mathrm{ZnS}$ layer improves electron lifetime and charge recombination, and thus the $\mathrm{ZnS}$ layer enhances the aging behaviour of $\mathrm{CdSe} / \mathrm{CdS} /$ $\mathrm{Zn}_{2} \mathrm{SnO}_{4}$ solar cells prepared via chemical bath deposition and SILAR methods [13].

There are also various studies investigating annealing-induced variations in the structural, morphological, electrical and optical properties of $\mathrm{ZnO}$ thin films. According to the results of these studies, after annealing, the crystal structures of $\mathrm{ZnO}$ thin films are enhanced [5] and the (002) orientation becomes weaker, while the (001) orientation becomes more prominent $[14,15]$. Furthermore, the results of XRD measurements show that the intensities of the diffraction peaks of $\mathrm{ZnO}$ films rise, and they shift to higher diffraction angles with annealing [16]. It is also reported that the grain sizes of $\mathrm{ZnO}$ structures increase [5, 14, 16, 17], while the surface roughness of $\mathrm{ZnO}$ films decreases [16]. The results of the study using different precursors to obtain $\mathrm{ZnO}$ thin films show that the crystal quality of $\mathrm{ZnO}$ thin films annealed at $350{ }^{\circ} \mathrm{C}$ is enhanced, and the intensities of diffraction peaks of XRD measurements are significantly increased; however, it is also noted that vacuum annealing does not change the preferential orientation of $\mathrm{ZnO}$ thin films [18]. We also note that increasing the annealing temperature beyond a certain value disturbs the crystal structure [15], and those new defects appear with post-annealing [14, 19].
Annealing enhances the transmittances of $\mathrm{ZnO}$ thin films [17], and their values increase with the increase of the the annealing temperature [14]. On the other hand, there are also studies reporting decreases in the transmittances at visible wavelengths after annealing [7, 18]. With annealing, the emissions of $\mathrm{ZnO}$ films increase at UV wavelengths and decrease at blue-green wavelengths [5, 7-9]. In addition, after annealing, the absorption edge energies of $\mathrm{ZnO}$ films show a red shift [16]. There are different results about the effect of annealing on the band gap energy $\left(E_{\mathrm{g}}\right)$. After annealing in oxygen ambient and open air, the $E_{\mathrm{g}}$ values of the $\mathrm{ZnO}$ thin films grown with the SILAR method decrease [16, 19]. Conversely, the $E_{\mathrm{g}}$ values of the $\mathrm{ZnO}$ thin films grown with the SILAR method increase after vacuum annealing with higher $E_{\mathrm{g}}$ values with the increase of the annealing temperature [9, 14, 17. Similar results are also obtained for the $\mathrm{ZnO}$ thin films grown with pulsed laser deposition and spray pyrolysis methods [7, 14.

In this study, $\mathrm{ZnO}$ nanorods (NRs) are deposited on FTO substrates by using the SILAR method, and the effects of annealing and aging on the structural and optical properties of $\mathrm{ZnO}$ films are investigated. The $\mathrm{ZnO}$ thin films are placed under UV light for $19 \mathrm{~h}$ for aging. In the literature, there is no study investigating the effect of the aging process on $\mathrm{ZnO}$ thin films deposited with the SILAR method, hence this study fills the gap in the literature.

\section{Deposition of $\mathrm{ZnO}$ thin films}

In the study, the SILAR method is used to deposit $\mathrm{ZnO}$ nanorods (NRs) on fluorine doped tin oxide (FTO). FTO substrates are cleaned in an ultrasonic bath with trichloroethylene, acetone and methanol for $300 \mathrm{~s}$, respectively. Cationic solutions are prepared with $0.1 \mathrm{M} \mathrm{ZnNO}_{4}$ and the $\mathrm{pH}$ value of the solution is set to 10 by adding $29 \%$ ammonia solution $\left(\mathrm{NH}_{4} \mathrm{OH}\right)$. After stirred for a few minutes at room temperature, the solution becomes ready. A cycle of the deposition process is as follows:

1) FTO substrates are immersed in the cationic solution for $30 \mathrm{~s}$ at room temperature;

2) FTO substrates are rinsed in $90{ }^{\circ} \mathrm{C}$ deionized water for $20 \mathrm{~s}$;

3) FTO substrates are dried in open air for $10 \mathrm{~s}$.

The $\mathrm{ZnO}$ NRs are deposited with 50 cycles. Possible reactions occurring during the deposition of ZnO NRs are, respectively, as in Eqs. (1) to (5) [20]: 


$$
\begin{aligned}
& \mathrm{Zn}\left(\mathrm{NO}_{3}\right)_{2}+2 \mathrm{NH}_{4} \mathrm{OH} \rightarrow \mathrm{Zn}(\mathrm{OH})_{2}(\mathrm{~s}) \\
& +2 \mathrm{NH}_{4}^{+}+2 \mathrm{NO}_{3}^{-} \\
& \mathrm{Zn}(\mathrm{OH})_{2}(\mathrm{~s})+4 \mathrm{NH}_{4}^{+} \rightarrow\left[\mathrm{Zn}\left(\mathrm{NH}_{3}\right)_{4}\right]^{2+}+2 \mathrm{H}_{2} \mathrm{O}+2 \mathrm{H}^{+}, \\
& {\left[\mathrm{Zn}\left(\mathrm{NH}_{3}\right)_{4}\right]^{2+}+\mathrm{H}_{2} \mathrm{O} \rightarrow \mathrm{Zn}^{2+}+\mathrm{NH}^{4+}+\mathrm{OH}^{-},} \\
& \mathrm{Zn}^{2+}+2 \mathrm{OH}^{-} \rightarrow \mathrm{Zn}(\mathrm{OH})_{2} \\
& \mathrm{Zn}(\mathrm{OH})_{2}(\mathrm{~s}) \rightarrow \mathrm{ZnO}(\mathrm{NR})(\mathrm{s})+\mathrm{H}_{2} \mathrm{O}
\end{aligned}
$$

The prepared samples are annealed at 200, 400 and $600{ }^{\circ} \mathrm{C}$ to investigate the annealing effects on the structural and optical properties of $\mathrm{ZnO}$ NRs. The annealing processes are applied in atmospheric conditions in an ash furnace for one hour. Also, optical aging is applied to the $\mathrm{ZnO} \mathrm{NRs}$ by keeping them under strong UV light for $19 \mathrm{~h}$ and the variations of structural and optical properties of the samples are observed. The samples are aged in the Esco Class II safety cabinet, using a $30 \mathrm{~W}$ UV fluorescent lamp emitting at $253.7 \mathrm{~nm}$ as a light source. The samples are placed as close as possible to the UV light source for the best aging condition. Irradiance of the source is calculated as $381.23 \mathrm{~W} / \mathrm{m}^{2}$.

The aim of these observations is to obtain useful information about the behaviour of $\mathrm{ZnO}$ thin films against aging to be able to produce $\mathrm{ZnO}$ thin film based long-lasting photonic devices.

\section{Results and discussion}

Surface morphologies and crystal structures of the samples are investigated by using SEM imaging and XRD measurements. The SEM photos of the samples are shown in Fig. 11. From these photos, the formation and homogeny distribution of $\mathrm{ZnO}$ NRs on the FTO substrates are observed. But there

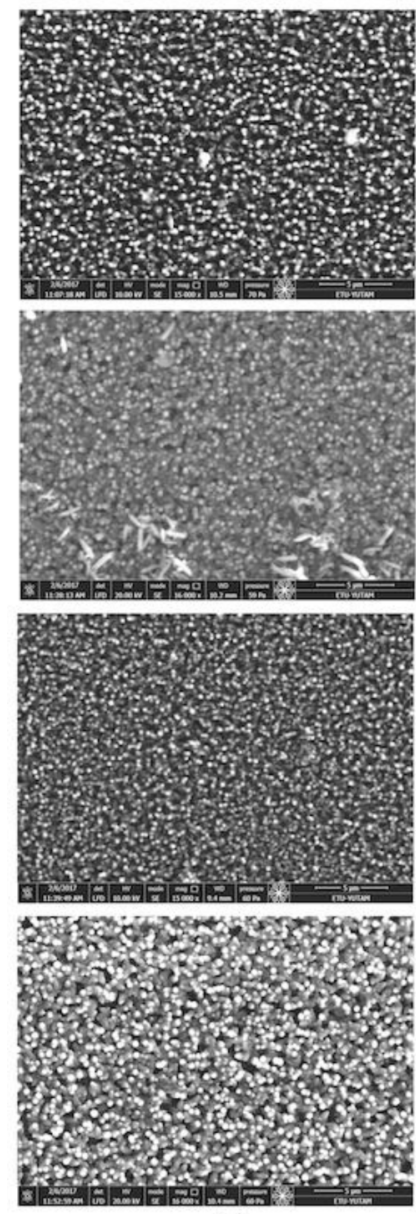

(a)
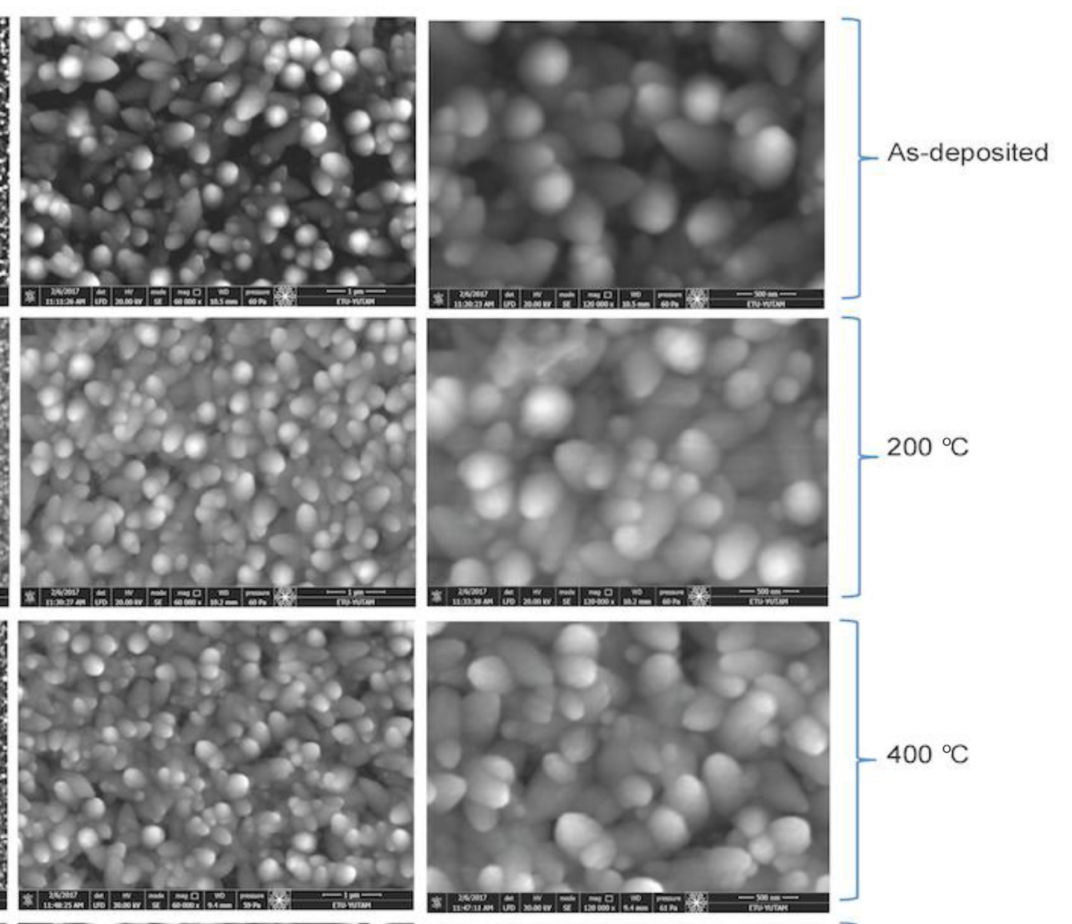

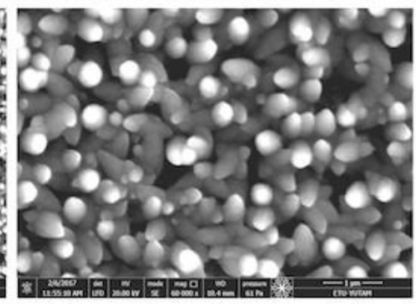

(b)

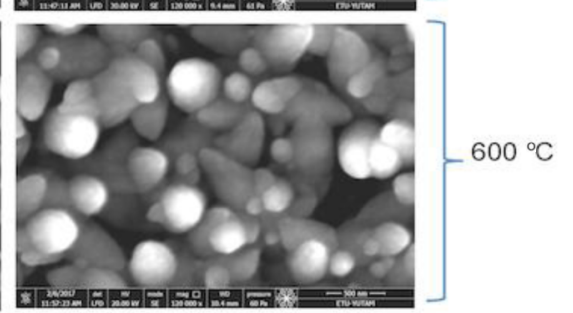

(c)

Fig. 1. SEM photos of as-deposited and annealed $\mathrm{ZnO}$ NRs with $16000 \times(a), 60000 \times(b)$ and $120000 \times(c)$ magnification ratios. 
are no significant changes in the grain sizes observed in the SEM images.

The obtained results of XRD measurements before and after aging of the samples are shown in Fig. 2. All the films are polycrystalline with a hexagonal wurtzite structure of $\mathrm{ZnO}$ according to the JCPDS Card No. 36-1451. Other peaks seen from the XRD measurements belong to the FTO substrate according to the JCPDS Card No. 461088. (100), (002) and (101) oriented $\mathrm{ZnO}$ peaks are dominant in the results. Especially the (002) peak of $\mathrm{ZnO}$ is higher than the other $\mathrm{ZnO}$ peaks on all graphs. Also, the results show that generally the peak intensities increase with annealing and so annealing enhances the crystal structure. The dominant (002) peak decreases at the annealing temperature of $400{ }^{\circ} \mathrm{C}$ and then slightly increases at $600{ }^{\circ} \mathrm{C}$. Peak intensities may decrease at 400 and $600{ }^{\circ} \mathrm{C}$ because of new defects in the structures due to high annealing temperatures.
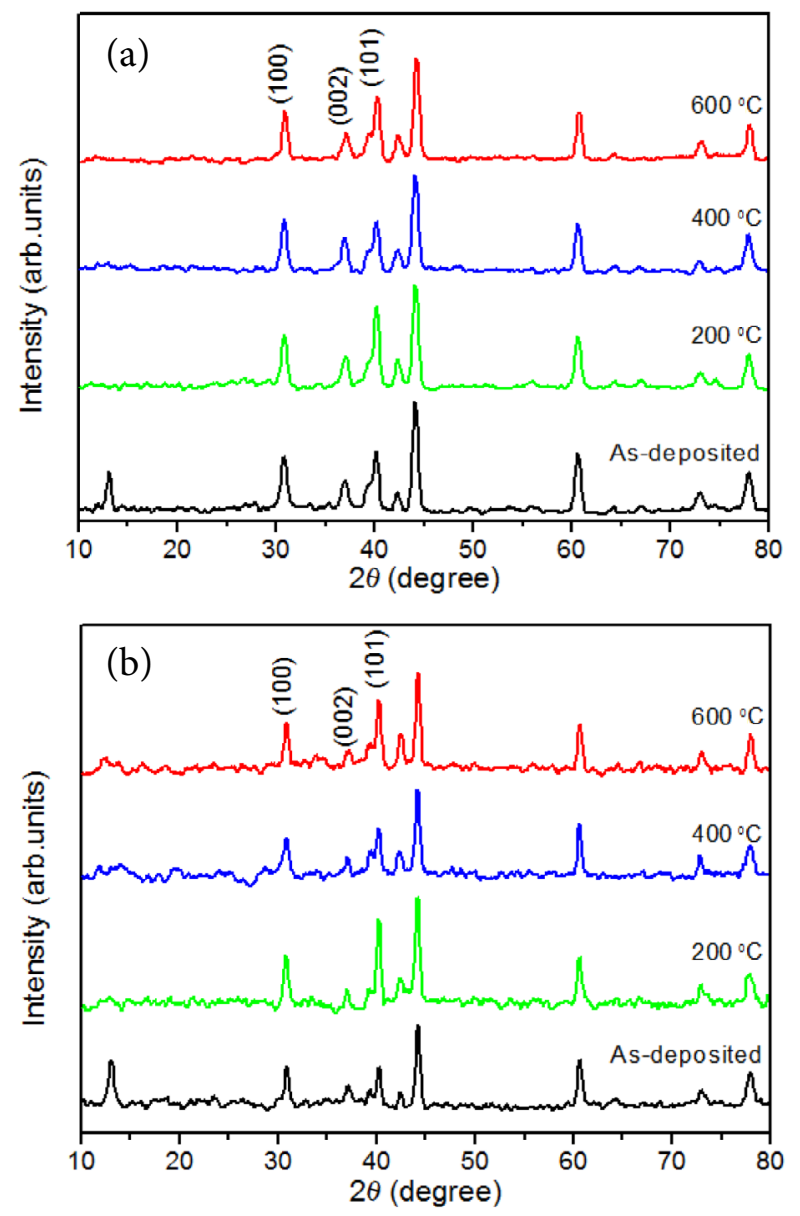

Fig. 2. XRD measurement results of the samples before (a) and after (b) aging.
After aging, the (002) peak intensities remain the same at the annealing temperature of $200{ }^{\circ} \mathrm{C}$ and increase at other annealing temperatures while the (100) peak intensities decrease. Also, the (101) peak intensities increase with aging, solely the (101) peak intensities of the samples annealed at $200{ }^{\circ} \mathrm{C}$ decrease. In general, the full width at the half maximum (FWHM) values of the XRD peaks decrease after aging. Decreasing of the FWHM values show improvements in the crystal structures with aging.

Photoluminescence (PL), transmittance and absorbance measurements are performed to examine optical properties of the samples and their variations induced by annealing and aging. Band gap values of the samples are also calculated. In Fig. 3 , the PL results of as-deposited and annealed samples are shown before and after aging.
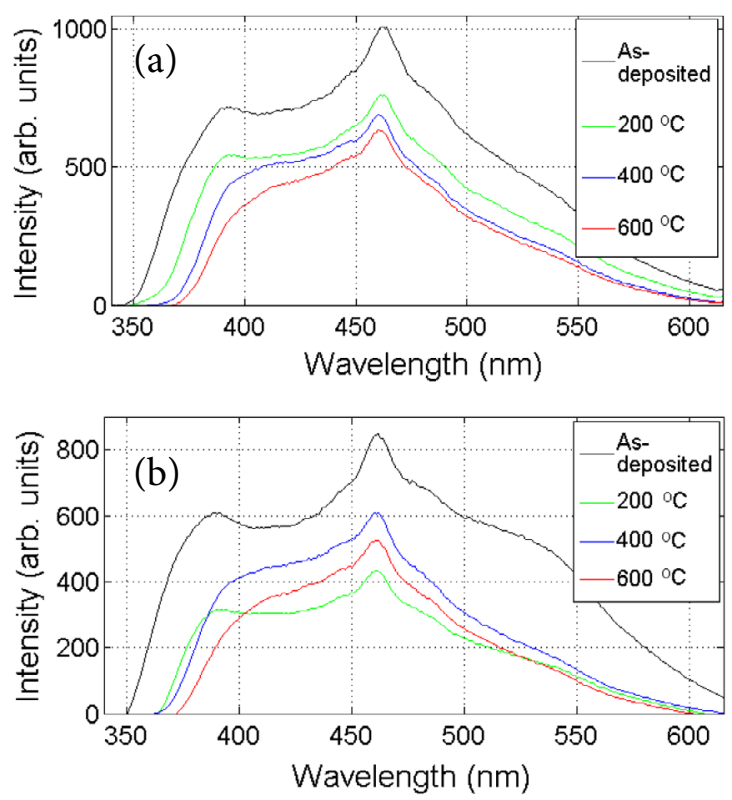

Fig. 3. PL measurement results of the samples before (a) and after (b) aging.

Two emission peaks around 395 and $464 \mathrm{~nm}$ are obtained from the PL results. Unlike the results presented in the literature, the values of both emission peaks are decreased with the increase of the annealing temperature. Especially, the edge emission peak emerging around $395 \mathrm{~nm}$ shifts and significantly decreases in intensity at 400 and $600{ }^{\circ} \mathrm{C}$ annealing temperatures while the deep level emission peak resulting from structural defects decreases only slightly (compared to the one at $395 \mathrm{~nm}$ ). Increasing of 
the number of oxygen vacancies induced by annealing can cause decreasing of near band edge emission intensity. After aging, the intensities of PL emissions decrease. The biggest drop is seen from the sample annealed at $200{ }^{\circ} \mathrm{C}$. Besides, after aging, the intensity of the PL emission around $530 \mathrm{~nm}$ increases for the as-deposited sample. This may be caused by formation of new defect levels in the as-deposited sample during aging. The transmittance results of asdeposited and annealed samples are shown in Fig. 4 before and after aging.

(a)
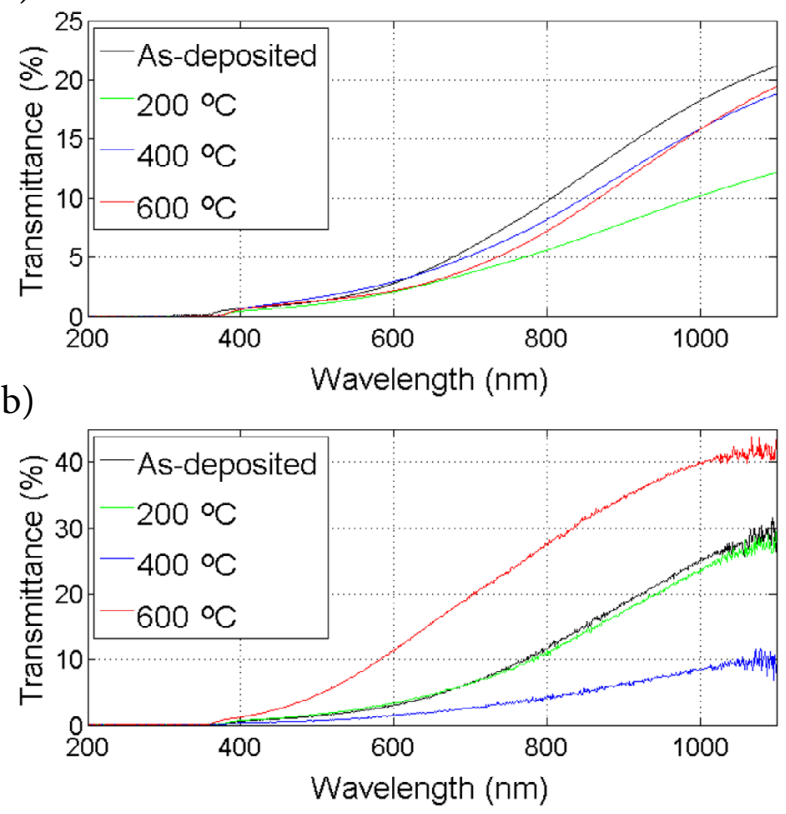

Fig. 4. Transmittance measurements of the samples before (a) and after (b) aging (coloured online).

Annealing causes decrease in the transmittance measurements of the samples. The transmittance of the sample annealed at $200{ }^{\circ} \mathrm{C}$ is most affected by this decrease. The optical transmittance increases in the case of thin films showing a highly preferred orientation along the c-axis. Upon light irradiation of the non-oriented film structure in which growth occurs along the (100), (002), and (101) directions, the dispersion at the opaque-grain boundaries causes a decrease of the transmittances [14]. Only the transmittance of the sample annealed at $400{ }^{\circ} \mathrm{C}$ decreases and other transmittances increase with aging. Especially, the transmittance of the sample annealed at $600^{\circ} \mathrm{C}$ increases substantially after aging. In Fig. 5, the absorbance plots of as-deposited and annealed samples are shown before and after aging.

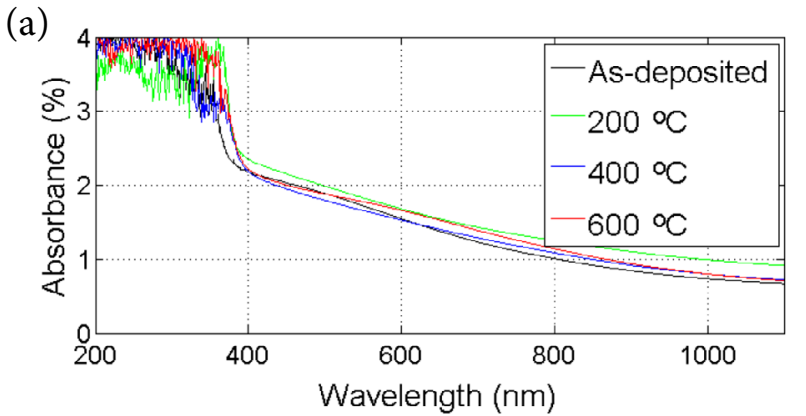

(b)

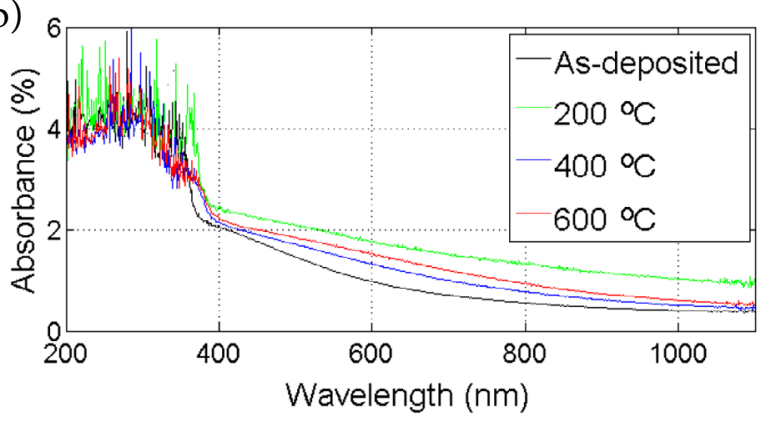

Fig. 5. Absorbance measurements of the samples before (a) and after (b) aging (coloured online).

The absorption edges of the annealed samples show a red shift, and after aging, the absorption edges show slight variations. The variation of the $(\alpha h v)^{2}$ values of as-deposited and annealed samples before and after aging are shown in Fig. 6 . The band gap energies calculated from Fig. 6 are tabulated in Table 1.

(a)

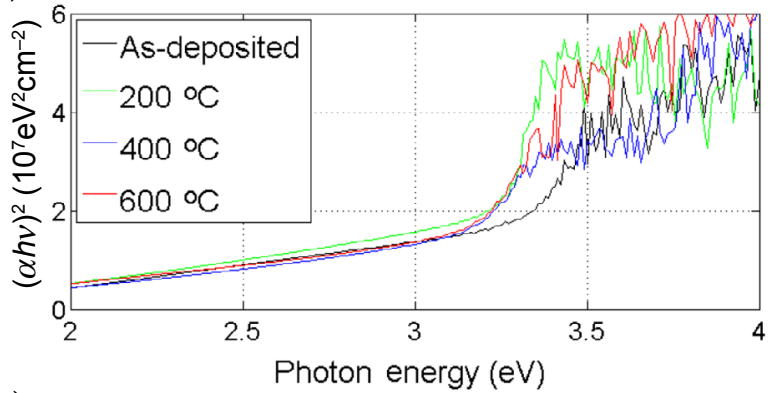

(b)

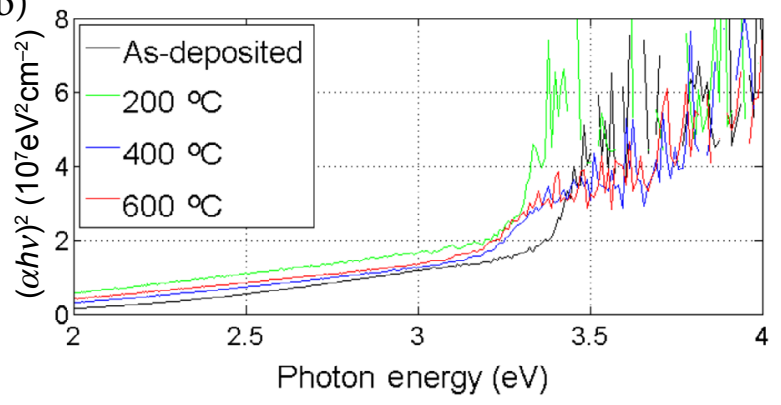

Fig. 6. $(\alpha h v)^{2}$ versus the photon energy plots of samples before (a) and after (b) aging (coloured online). 
Table 1. Band gap energies of the samples before and after aging.

\begin{tabular}{c|c|c}
\hline Annealing temperature & Band gap energy (before aging) & Band gap energy (after aging) \\
\hline As-deposited & $3.16 \mathrm{eV}$ & $3.29 \mathrm{eV}$ \\
\hline $200^{\circ} \mathrm{C}$ & $3.14 \mathrm{eV}$ & $3.25 \mathrm{eV}$ \\
\hline $400^{\circ} \mathrm{C}$ & $3.00 \mathrm{eV}$ & $3.04 \mathrm{eV}$ \\
\hline $600^{\circ} \mathrm{C}$ & $2.98 \mathrm{eV}$ & $3.00 \mathrm{eV}$ \\
\hline
\end{tabular}

After annealing, the band gap energies of the samples decrease. It may be due to the presence of zinc hydroxide forms such as $\mathrm{Zn}(\mathrm{OH})_{2}$. As the annealing temperature increases, the band gap energies decrease due to the removal of zinc hydroxide and the decrease of defect levels which is a more common phenomena in chemically deposited thin films. With annealing, the stacking faults of the samples are also decreased and orientations of the individual crystallites enhance, so defect free grain boundaries occur. In addition, the decrease in the band gap energies can be attributed to the increase in grain sizes. Annealing-induced shifts of the absorption edge energies to lower energies may occur due to the localization of charges in individual nanocrystals and may be attributed to the grain size-dependent properties of the band gap energy. Similar red shifts in band gap energy values for the films with smaller thickness and/ or grain sizes have been reported for chemically deposited thin films [21]. Also, after aging, slight increases are observed at the band gap energies of the samples.

\section{Summary}

Surface morphologies, crystal structures and optical properties of $\mathrm{ZnO}$ thin films, and variations in these properties induced by annealing and optical aging are examined. One of the $\mathrm{ZnO}$ thin films prepared with the SILAR method is not annealed and the others are annealed at 200,400 and $600{ }^{\circ} \mathrm{C}$ in open air. The examination of these samples shows the annealing effect on the properties of $\mathrm{ZnO}$ thin films. Also, the samples are optically aged under UV light for $19 \mathrm{~h}$.

SEM photos and XRD measurements are used to investigate the structural properties of $\mathrm{ZnO}$ thin films, meanwhile photoluminescence, transmittance and absorbance measurements are used to investigate the optical properties. The results show that annealing enhances the crystal structures and surface morphologies of thin films and the aging effect on the properties of thin films is related to the annealing temperature. The $\mathrm{ZnO}$ thin films annealed at $200{ }^{\circ} \mathrm{C}$ show better aging responses than the others.

\section{References}

[1] D.J. Rogers, P. Bove, E.V. Sandana, F.H. Teherani, R. Mcclintock, and M. Razeghi, Solid state deep UV emitters/detectors: zinc oxide moves further into the ultraviolet, Laser Focus World 49(10), $1-15$ (2013).

[2] Y. Zhang, M.K. Ram, E.K. Stefanakos, and D.T. Goswami, Synthesis, characterization, and applications of $\mathrm{ZnO}$ nanowires, J. Nanomater. 2012, 1-22 (2012).

[3] A. Raidoua, M. Aggoura, A. Qachaoua, L. Laanabb, and M. Fahoumea, Preparation and characterisation of $\mathrm{ZnO}$ thin films deposited by SILAR method, Condens. Matter 12(2), 125-130 (2010).

[4] S.B. Jambure, S.J. Patil, A.R. Deshpande, and C.D. Lokhande, A comparative study of physicochemical properties of CBD and SILAR grown $\mathrm{ZnO}$ thin films, Mater. Res. Bull. 49, 2588-2592 (2014).

[5] Y. Chen, J. Nayak, H.U. Ko, and J. Kim, Effect of annealing temperature on the characteristics of ZnO thin films, J. Phys. Chem. Solids 73, 12591263 (2012).

[6] T. Ren, H.R. Baher, and K.M. Poduska, Optical absorption edge shifts in electrodeposited $\mathrm{ZnO}$ thin films, Thin Solid Films 515, 7976-7983 (2007).

[7] F.K. Shan, B.C. Shin, S.C. Kim, and Y.S. Yu, Optical properties of As doped $\mathrm{ZnO}$ thin films prepared by pulsed laser deposition technique, J. Eur. Ceram. Soc. 24, 1861-1864 (2004).

[8] L. Xu, L. Shi, and X. Li, Preparation of nanocone $\mathrm{ZnO}$ thin film and its aging effect of photoluminescence, Appl. Surf. Sci. 255, 5957-5960 (2009). 
[9] F.K. Shana, G.X. Liua, W.J. Leea, G.H. Leea, I.S. Kima, B.C. Shina, and Y.C. Kimb, Transparent conductive $\mathrm{ZnO}$ thin films on glass substrates deposited by pulsed laser deposition, J. Cryst. Growth 277, 284-292 (2005).

[10]F.K. Shan, Z.F. Liu, G.X. Liu, W.J. Lee, G.H. Lee, I.S. Kim, B.C. Shin, and Y.S. Yu, Aging and annealing effects of $\mathrm{ZnO}$ thin films on GaAs substrates deposited by pulsed laser deposition, J. Electroceram. 13(1-3), 195-200 (2004).

[11]B.G. Guzeldir, M. Saglam, A. Ates, and A. Turut, Effects of ageing on the electrical characteristics of $\mathrm{Cd} / \mathrm{CdS} / \mathrm{n}-\mathrm{Si} / \mathrm{Au}-\mathrm{Sb}$ structure deposited by SILAR method, J. Phys. Chem. Solids 72, 15061514 (2011).

[12]M. Saglam and B. Guzeldir, Time-dependent of characteristics of $\mathrm{Cu} / \mathrm{CuS} / \mathrm{n}-\mathrm{GaAs} / \mathrm{In}$ structure produced by SILAR method, Mater. Res. Bull. 81, 55-62 (2016).

[13]K. Kim, J.E. Park, E.S. Park, Y.C. Park, J. Kim, J.C. Im, and M.J. Lee, ZnS-passivated CdSe/CdS Co-sensitized mesoporous $\mathrm{Zn}_{2} \mathrm{SnO}_{4}$ based solar cells, Electrochim. Acta 121, 223-232 (2014).

[14]K. Ravichandran, M. Vasanthi, K. Thirumurugan, B. Sakthivel, and K. Karthika, Annealing induced reorientation of crystallites in $\mathrm{Sn}$ doped $\mathrm{ZnO}$ films, Opt. Mater. 37, 59-64 (2014).

[15] V. Shelke, M.P. Bhole, and D.S. Patil, Open air annealing effect on the electrical and optical properties of tin doped $\mathrm{ZnO}$ nanostructure, Solid State Sci. 14, 705-710 (2012).
[16]S.C. Shei, P.Y. Lee, and S.J. Chang, Effect of temperature on the deposition of $\mathrm{ZnO}$ thin films by successive ionic layer adsorption and reaction, Appl. Surf. Sci. 258, 8109-8116 (2012).

[17]P.V. Rajkumar, K. Ravichandran, M. Beneto, C. Ravidhas, B. Sakthivel, and N. Dineshbabu, Enhancement of optical and electrical properties of SILAR deposited $\mathrm{ZnO}$ thin films through fluorine doping and vacuum annealing for photovoltaic applications, Mater. Sci. Semicond. Process. 35, 189-196 (2015).

[18]K. Ravichandran, P.V. Rajkumar, B. Sakthivel, K. Swaminathan, and L. Chinnappa, Role of precursor material and annealing ambience on the physical properties of SILAR deposited $\mathrm{ZnO}$ films, Ceram. Int. 40, 12375-12382 (2014).

[19]M.A. Yildirim and A. Ates, Influence of films thickness and structure on the photo-response of $\mathrm{ZnO}$ films, Opt. Commun. 283, 1370-1377 (2010).

[20]H. Güney and M.E. Ertarğın, Effective annealing of $\mathrm{ZnO}$ thin films grown by three different SILAR processes, East. Anat. J. Sci. 1, 20-24 (2015).

[21]A. Ghosha, N.G. Deshpande, Y.G. Gudagea, R.A. Joshi, A.A. Sagade, D.M. Phase, and R. Sharma, Effect of annealing on structural and optical properties of zinc oxide thin film deposited by successive ionic layer adsorption and reaction technique, J. Alloys Compd. 469, 56-60 (2009).

\title{
ATKAITINIMO IR SENDINIMO ŠVIESOJE ITAKA OPTINĖMS IR STRUKTŪRINĖMS ZnO PLONŲJŲ SLUOKSNIŲ, AUGINTŲ SILAR METODU, SAVYBËMS
}

\author{
C. Duman ${ }^{\mathrm{a}}, \mathrm{H}$. Guney ${ }^{\mathrm{b}}$ \\ ${ }^{a}$ Erzurumo technikos universitetas, Erzurumas, Turkija \\ ${ }^{\mathrm{b}}$ Ahro Ibrahimo Ceceno universitetas, Ahras, Turkija
}

